\title{
Inspiring Desire: A new materialist bent to doctoral education in Arts and Humanities
}

\author{
Susan Carter $^{\mathrm{a} *}$ and Vicky Gunn ${ }^{\mathrm{b}}$
}

Centre for Research and Learning in Higher Education, The University of Auckland, Auckland, New Zealand; and Glasgow School of Art, Glasgow, Scotland, UK

\begin{abstract}
Doctoral learning entails transition from experienced student to stance-defending researcher, exposed to international critique: a disorientation and reorientation into a new identity. Arts and Humanities candidates typically navigate these moves without much of a map, choosing their own topics, avoiding the more externally defined approach available to STEM students, and mapping out their own research routes. They are often driven by desire and passion for their topic. Much of each candidate's core identity will be inflected by this transition of emergence, a transition that involves their embodiment, emotion and social persona.
\end{abstract}

With intense and sometimes-uncomfortable transition in mind, and desire as driver, new materialism, namely nomadic feminism and queer theory, can inform doctoral pedagogy in Arts and Humanities. The destabilization of normativity opens the potentials and challenges of inhabited and performed identity. Queer theory's longstanding negotiation of social and personal tensions gives a heuristic model for understanding doctoral identity transition.

Key words: doctoral identity, queering doctoral pedagogy, doctoral learning, new materialism, desire, doctoral pedagogy

\section{Introduction: our line into doctoral learning}

Education, like all human enterprises, is a function of identity and desire...The difficulty of education is...that engaging and directing identities and desires is fraught with multiple obstacles.... (Bracher, 2002: 93)

Sexual desire is rarely less than potent, often subversive, and frequently messy. Differently othered sexual desire is considered thus even more so. These characteristics and

\footnotetext{
${ }^{a}$ Corresponding author: s.carter@auckland.ac.nz
} 
their association with sexual orientation and identity are a central thread in queer theory. Feminist theory also fingers the disruptive force of desire, challenging assumptions about the given nature of desire (Butler, 1990), for example, when Braidotti (1996) maps the time-honoured view of female desire as monstrous in order to challenge that view. Desire, then, is judged and theorised from different perspectives. Yet, despite perspectival contestation, desire is animated by emotions of intense pleasure (Swan, 2005), driving human activity according to its own bent.

Learning at the doctoral level, too, is potent, subversive and messy. It is especially so for doctoral students whose Social Science work pivots around their own identity, who inhabit etic and emic positionalities. They perform a paradox: being subjectively within their research field at the same time as objectively analysing and curating to ultimately make an objective thesis that somehow incorporates aspects of who they are. Like those in Social Science, and unlike STEM disciplinarians, Arts Humanities researchers generally choose their own topic and thesis according to their personal passion. Thus our $\mathrm{PhD}$ candidates are disciplinarily at once both normative and queer: 'Discontinuities, contradictions and disruptions of identity' trouble some of those 'emerging....in a mainstream university setting' (Webber, 2009: 1). Although other disciplines do engage with a reflexive praxis involving emic and etic positionality (particularly applied research in the medical sciences), this is a quasi-essential component of the Arts Humanities disciplinary whole. Our doctoral students do not join prescribed projects, and work in research teams with daily guidance, but choose their own topic and methods, usually theoretical, and are thus more experimental and creative. From choices of topic to forms of research practice, Arts and Humanities often implicitly demand that the self be explicitly situated within the research project: desires, identity, texts, and visuals become formally bound together. However, despite Bracher's relatively uncontroversial observation of identity and desire enactments in education, research exploring $\mathrm{PhD}$ learning seldom addresses the embodied and changing human dimensions. Nomadic feminism offers an antidote by factoring in the self's embodiment of gender, culture, class etc., productively troubling homogeneity. To design healthy pedagogic environments, we need to address learning's embodiment as engendering certain types of doctoral orientation.

We draw on new materialism to tap the driving forces of desire regarding doctoral learning. We contend that, as painful as doctoral emergence can be, it is also driven by desire to succeed, by hope, and by passion, often obsession, towards the topic. The mix of challenges and desire colour the doctoral journey. Because queer and feminist theory grow 
from lived experience, new materialism provides a useful overarching paradigm for interpreting the embodiment of doctoral learning. New materialism encapsulates that we become who we are through what we do and what we do reconfigures ideas and things to expand the potential for action and production (Keane, 2013; Grosz, 2010). Our argument assumes that the disorientating experience of growth enables creation of new knowledge, so we draw upon theories that configure disorientation as a positive and enabling process. As Braidotti (Delphijn and Van der Tuin, 2012: 32) puts it:

Between the "no longer" and the "not yet," desire traces the possible patterns of becoming....[sketching] the conditions of intersubjective encounters between the no longer and the not yet, through the unavoidable accident of an insight, a flush of sudden acceleration that marks a point of no return.

New materialism helpfully foregrounds embodied difference, outlining the tensions between the normative and queer in any given situation-Arts and Humanities candidates commonly negotiate between normative generic requirements of the doctorate and their own creative preference. Desire's pleasures (see for example, Swan, 2005) make deviancy's compulsion and troublesomeness worthwhile. From this perspective, we use the works on queer orientations by Sara Ahmed, Rosi Braidotti and others to reframe doctoral experiences in Arts and Humanities.

This article had its origins in Vicky's personal engagement in doctoral teaching and learning. She experienced the ways that clashing metanarratives within research methodologies can play out in the relationship between student, supervisor and discipline because of intersections of sexual orientation, desire and the body. She reflected on how disruptions emanate from sexual orientation--the role the body plays in broader academic and intellectual orientations. Until recently, embodied approaches to higher education learning have failed to attract much scholarly attention at either undergraduate or postgraduate levels; new materialism offers doctoral pedagogy new insights.

First, then, the body. Although lived academic experience plays out on the body, investigations of the theory-lived experience fit are often oblique. One rare article 'storys' the play of academic pressure on the body (Sparkes, 2007). Another considers the erotic pleasure of teaching, when arousing students' interest in the topic, tantalizing them, and mutually savouring ideas (Swan, 2005) — such pleasure may be found by both student and supervisor in doctoral research, reinforcing driving desire.

Researchers are reincorporating the doctoral body (Hopwood and Paulson, 2012; Carter, 2012). They have queered the social imaginary of postgraduate education (Maritz and 
Prinsloo, 2015); supported queer postgraduates in the visual arts (Ings, 2015); and queered the affective politics of doctoral education (Burford, 2015). There are, nonetheless, still considerable absences around aspects of embodiment, particularly the interactions between identity orientation, affect and doctoral oriention towards or away from research approaches (Gunn and McAllister, 2013; Gunn, 2014a) We add a new materialist consideraton of the tensions inherent in doctoral learning and the desires driving it.

\section{Doctoral learning: A troublesome transition for some}

We come to embody, as though we never learned them, the insidious and tacit knowledges... how to express recognition of competence; and how to express our recognition that what someone does or says falls outside the domain of the appropriately academic. ... we learn these things through multiple social and discursive sites. (Petersen, 2007: 478)

Experience and literature show that doctoral learning is seldom painless and requires new ways of being as well as thinking. Doctoral students must cross conceptual thresholds (Kiley and Wisker, 2009; Wisker, Cheng, and Morris, 2010), as when they understand the contentions of their topic and see how to situate themselves critically, for example. Doctoral 'conceptual threshold crossing' develops threshold concepts theory (Meyer and Land, 2005), which describes difficult learning, usually within disciplines: by definition, threshold concept learning is transformative, troublesome, irreversible, integrative and bounded. Doctoral learning is often troublesome: for example, until they situate themselves in their topic's contentions, candidates are not sure what critical analysis means or how to perform it. Then, doctoral students seek new knowledge: 'The issue, for some at least, is not only about being able to fruitfully learn despite not knowing (where 'not knowing' is framed as an obstacle to be overcome) but to deliberately cultivate and sustain a state of not-knowing as a learning strategy' (Cherry, 2005: 316). The multiplicity of guidebooks for doctoral students bears testament the fact that this is hard (Bolker, 1998; Brause, 2000; Cantwell, 2006; Denholm and Evans, 2006; Dunleavy, 2003; Murray, 2011; Thomson and Walker, 2010; White, 2011 to mention a few). Research pays attention to high rates of doctoral attrition that signal difficulty (Lovitts, 2008; Lovitts and Nelson, 2000), and demonstrate the discomfort of international study (Ali and Kohun, 2007; Grimshaw and Sears, 2008; Wu, 2013). The chaos of not-knowing can be frightening, yet it also offers Arts and Humanities students exhilaration in striking new directions that are meaningful to their embodied selves. 


\section{The social negotiations of doctoral sameness and difference}

There is no 'universal' knowledge. There is no 'foundational' knowledge. Knowledge is contingent and socially constructed all the way up and all the way down. (Bruffee, 1999: 267)

The social negotiations of successful doctoral learning are multiple. Some developing doctoral identities must negotiate "the subjective outcomes of political consciousness and choice.... and structural constraints that condition the opportunities to access and express identity' [italics in original] (Webber, 2009: 1). Some must also reconcile their own somatic experience with theory; the fit can be uncomfortable. Theory does not always feel authentic when weighed against the more dissonant experiences of being. Supervision plays a major part; hence, there are guides for supervisors (Evans, 2010; Melin Emilsson and Johnsson, 2007; Murray, 2011; Watts, 2010; Wisker, 2012) recognising that this professional relationship sometimes collapses because it is also a personal one. Furthermore, 'writing and research is never innocent' (Webber, 2009: 2), and frequently troubles doctoral novices (Aitchison and Pare, 2012; Kamler and Thomson, 2006). Literature suggests that the triad of textual interaction between supervisor, student and thesis entails more than just transactions operating to set procedure (Grant, 2003). It is clear that visible materialisations are merely part of a much larger experiential, embodied ecosystem.

In the best case scenario, the doctoral student experiences learning as an adventure rather than a painful reshaping of identity. Postgraduate learning has been theorised by Petersen (2007) as 'boundary work,' a formulation of the student's academic self during which they learn to recognise ' $I$ am someone who is this way and therefore $I$ could not possibly become that kind of academic' [italics in the original] (Petersen, 2007: 480-481). Or as Ahmed puts it, "the utterance "I can" points to the future only insofar as it inherits the past.... The body emerges from the history of doing, which is also a history of not doing, of paths not taken, which also involves the loss...of what might have followed from such paths' (Ahmed, 2006: 159). Additionally, the construction of being this way and not that way sometimes entails what Ahmed and Stacey (2001) call 'thinking through the skin,' a metaphor that draws together the cerebral 'thinking through' and the corporeal in a productive ambiguity. In regard to doctoral learning as boundary work, Petersen (2007: 480) points out that deviants work the boundaries, being tugged in by boundary maintainers, and sometimes managing to push out beyond boundaries, and expand the space of academic possibility. 
The doctorate's social negotiations must establish a researcher identity that is, paradoxically, 'same, same but different' (Laurs, 2013). The thesis must demonstrate that it meets clearly-defined generic criteria, including that it contributes something original, its point of difference. Bemusing on the inaccuracy of the cliché 'as like as two peas in a pod', Ahmed (2006: 124) points out that

Anyone who has shelled peas knows that peas [in a pod] are not all alike and that seeing them as alike is already to overlook some important differences....the very proximity of pea to pea, as well the intimacy of the dwelling that surrounds them like a skin, shapes the very form of the peas. Likeness is thus not 'in' the peas, let alone 'in' the pod, but rather is an effect of their contiguity, of how they are touched by each other and envelop each other (Ahmed , 2006: 124).

Revisiting the (un)likeness of peas provides an analogy for doctoral learning. The productive doctoral 'pod' comprises a complex combination of contiguous social interactions shaping both the novice researcher and their research: discipline, methodology, theoretical bent, institution, department, gender, sexual preference, age, class, culture and so on. Bound by contiguity, doctorates are not all alike. New materialism and queer theory give a frame for the troublesome nature of their difference, and the pleasure of contesting normativity. Doctoral learning offers a chance to track new orientations through mainstream discourse.

Queer theory particularly applies to deviants who insist on pushing the boundaries rather than being compliant subjects within them; some doctoral students inhabit exactly that deviant position with their boundary learning work. They are driven by desire for innovation. The doctorate's requirement for new knowledge pushes all candidates into working those boundaries of the known, yet some Arts and Humanities candidates swing further off than most, alone on the edge.

\section{Deviant desire as research method: positive potential}

...keep open the possibility of changing directions and of finding other paths, perhaps those that do not clear a common ground, where we can respond with joy to what goes astray. (Ahmed, 2006: 178)

Individual differences, particularly gender, sexual preference, age, class, culture, quite commonly fuel desire to blaze new Arts and Humanities trails. Vicky's queer/lesbian experience as a researcher and supervisor in an interdisciplinary arena led her to note how dissonant encounters with common disciplinary assumptions, apparently intellectual in nature but fully embodied in experience, caused significant learning breakthroughs. She sees 
authentic subjectivity as a key tenet of student-centred learning, not only how we learn but also how we come to understand ourselves and learn to be. Weaving together her own personal experiences and meaning-making, new materialism, and the conceptual work of Sally Munt, Jack Halberstam and Sarah Ahmed enables Vicky to understand authentic subjectivity as linking the perceiving self and associated desires while eluding an oppositional binary of biological determinism and social constructivism (Munt, 1998; Halberstam, 1998; Ahmed, 2006). In an educational theory context, faced with a heavy dependence on the socially constructed nature of learning, queer authentic subjectivity generates intellectual abrasions, moments of, 'but what if?' Vicky experienced the way that a researcher's own belief--embodied, sensual and based on intimate exchanges outside the research community-will over-ride epistemological expectations (see too Toynton, 2007).

Within western cultural frameworks, which we would argue are deeply embedded within Arts and Humanities study in western universities, competing meta-narratives operate in dialogue with each other. Arts and Humanities are premised epistemologically on the belief in multiple interpretations, yet researchers working closely with historical, cultural and social primary material are acutely aware that the cultural biases they are born into underpin much of what is studied. We research in a fallen world, shaken out from the rigidly heteronormative foundations of Eden. One pedagogical response is recognition that 'experimenting with thinking is what we all need to learn. That implies the de-territorializion of the very sexual difference we started out from' (Braidotti, interviewed by Delphijn and Van der Tuin, 2012: 29). A LGBTQ researcher undertaking LGBTQ-focused doctoral studies may well be discomfited that none of the meta-narratives of discipline expectations explains their way of being as it manifests through their bodies. Yet this dislocation means they are well-placed to cut a desire line differently, through new territory, laying a path others might find inviting to follow.

Queer dissonance emerges from LGBTQ experience and shows something important about how the doctoral process in general works. Identity must be constructed within competing meta-narratives, through which doctoral students must draw their own line, orienting from the desire that drives them into research. We suggest that queer theory offers insight into the embodied experience of doctoral studies more broadly than just for the LGBTQ community. This is especially the case if 'queering' is focused on destabilizing normativity in research methodologies. When researchers design a new methodology, or theorise in new ways, they pioneer what Ahmed calls 'desire lines.' Ahmed takes her 
metaphor from the fact that "in landscape architecture they use the term "desire lines" to describe unofficial paths, those marks left on the ground to show everyday comings and goings, where people deviate from the path they are meant to follow' (Ahmed, 2006: 19-20). Deviance from the norm can be positive in bringing forth new theoretical paths. For example, Linda Tuhiwai Smith (1999) spells out a research framework based on Māori cultural values centred around community in contrast to many western methods: Kaupapa Māori methodology is now much used by indigenous researchers and drawn upon by others. In doing so, they engage in significant socio-political work as 'subjects reproduce[ing] the lines that they follow' (Ahmed, 2006: 17): by walking a line that consciously deviates from western research methodological highways, they establish it as a road that may be taken through doctoral study's transition.

The nuances of personal identity that might lead to the choice of a deviant desire line problematise doctoral learning in interesting ways. Thesis writing requires building a convincing academic persona through voice in prose (Aitchison and Pare, 2012; Kamler and Thomson, 2006; Lee and Aitchison, 2009). This voice often negotiates a gendered positionality within the complex social implications of gender and its theorisation (Carter, 2012). The body, with its emotions and its desires, is the site of one doctoral output, the researcher herself.

Furthermore, the body is also a site of the pleasure of chasing ideas through the labyrinth that leads to a completed doctorate. As one doctoral student identified, '...you need to have a crush on your theorist,' which caused reflection in her writing group about 'what made ideas "sexy," ...[and] 'the difference between flirting... and developing a crush' (Thesen, 2014: 165). The ideal theoretical position authentically fits self in a sound sustainable working relationship: me and my theory-we're likely to be an item for a while. It's a cliché that Arts and Humanities' doctoral students need to 'follow their passion'maybe the case is more that they need to find ways to keep that passion alive as sustenance for surviving doctoral challenges.

The need for timely completion sometimes seemingly menaces satisfactory reconciliation of one's personal experience and research methodologies: 'to follow a line takes time, energy and resources, which means that the "line" one takes does not stay apart from the line of one's life...If we give up on the line that we have given our time to, then we give up more than a line; we give up a certain life we have lived, which can feel like giving up on ourselves' (Ahmed, 2006: 17-18). We are not proposing that Arts and Humanities' doctoral students should be given more time for their troublesome negotiations, but 
emphasising that queer theory offers a way of understanding the need for and benefits of deviation. Queer theory is premised upon the idea of driving desire, desire that motivates, even to run through sometimes violent objections to difference, in order to follow lines that might, perhaps, become visible to others. Desire for difference lies at the heart of doctoral originality; accepting that it is hard, celebrating the right to difference, may energise those struggling to blaze a trail through challenging terrain.

\section{Queering doctoral learning: a story told from the body}

Orientations towards sexual objects affect the things that we do, such that different orientations, different ways of directing one's desires, means inhabiting different worlds. (Ahmed, 2006: 68)

This paper took energy from that notion that queering doctoral learning gave a theoretical frame to make sense of the common discomfort of transition through becoming into being. Bartlett and Bold (2013) evocatively call the troublesome incarnation of new knowledge, 'carnal knowledge.' When the meta-narratives of biological determinism and social constructivism are enacted through research methodologies tstudents are taught to accept, within disciplinary communities where they feel alien, intersections with bodily experience can generate tensions within the interpersonal and inter-subjective realms. In such a situation, leanings towards or away from disciplinary norms, is how, perhaps painfully, learning occurs. This learning is best understood as positive deviancy, where what bends away from the known, and finds voice to speak its own bent, extends the known into new understanding. At the same time, much doctoral learning needs to be recognized as driven by pleasure 'in the flirtatiousness of intellectual debate, in the game of competing, [and]...the sexiness of winning...' (Kirby, 1994: 19). Here we draw together desire, deviation, troublesomeness, and the deep satisfaction of renewed desire.

\section{Theory, body, desire: an equation}

Voice remains tied to the body while also giving itself up to the incorporeality of 'the word' as meaning, truth or idea. (Maclure, 2009: 97)

Lived bodily encounters have the practical power to destabilize over-simplifying categories of human experience. Theory negotiates through the Body: the Freudian penis engendering anxiety and envy; Klein's maternal breast, primal never-satisfied desire. Feminist and queer theory reinscribe the theoretical Body, honing in on "the everyday work of dealing with the 
perceptions of others... and the violence that might follow when perceptions congeal into social forms' (Ahmed, 2006: 107). Medievalist Felicity Riddy seized the Body back from theory by paying heed to the 'everyday body,' with a humble little b signalling quotidian needs: a coffee, the toilet (Riddy, 1994). The everyday doctoral body is likely to have shoulders stiff from writing. It serves the desires bound into doctoral learning: completion, success, recognition. The act of creating an academic identity through thesis writing grapples with ideas of the self, ironically in a denial of corporeality. We wonder to what extent inspirational desire might lie in the somatic, driven by hormones and the body's rhythmic cycles, while inflected by the social values played out on the body (Greenblatt, 2005) for candidates? The doctoral body steps up to speak at a conference, sits in a tutorial as the teacher facing students, stands and lectures in a large theatre. How do colleagues, professors, students, see this body being the novice researcher? Is it desirably professional? Is it interesting? How does the new researcher's body feel from within-is it drawn to talk in this way? Most doctoral students struggle to be desirable and interesting, seeking endorsement from the significant others of academia (Martusewicz, 1997). These self-conscious bodies perform doctoral becoming.

\section{The doctoral body inflects towards or away}

If sexual orientation is understood as something one 'has,' such that one 'is' what one 'has,' then what one 'is' becomes defined in terms of one's desire, as an attraction that pulls one towards others. (Ahmed, 2006: 69-70)

Theoretically this paper takes as its point of departure Sara Ahmed's work. The central tenet of our argument is that her understanding of embodied orientation maps usefully onto doctoral learning. We suggest that intrinsically-linked desires and bodies might inform or influence what is learned in terms of doctoral education's fundamental aims. For Arts and Humanities candidates, theory is strongest when it is authentic to the researcher's embodied experience. Supervisors could consider what individual students are prepared to learn without compromising their embodied Self. As is noted of academic identity, authorised institutional stories cannot drown out the personal narratives that speak from embodied experience (Churchman and King, 2009: 508) — there is a need for 'promoting spaces where multiple stories can resonate, grow and sustain identities' (515).

\section{Embodied doctoral experience: a positively queer practice?}


The task is to trace the lines for a different genealogy, one that would embrace the failure to inherit the family line as the condition of possibility of another way of dwelling in the world. (Ahmed, 2006: 178)

Positive deviance evolved from medical practitioners' recognition that 'in most settings, at risk individuals follow uncommon beneficial practices and consequently experience better outcomes than their neighbours who share similar risks' (Marsh et al., 2004: 1177). They realized that positive deviancy leads to promising new methods, behaviours, and understandings, a recognition picked up by organizational theorists, who identified amongst positive deviants behaviours that benefit corporations, such as organizational citizenship, whistle-blowing, creativity and innovation (Spreitzer and Somenshein, 2004). Those who trail-blazed queer, feminist and decolonizing theory can be seen as positive deviants, because they meet the criteria: they have reacted to at-risk situations and strengthened themselves in those positions. Their research could be termed whistle-blowing when it demonstrates that common behavior is heteronormative or gender and culturally biased; they provide citizenship and leadership within communities; and create new paths for others to walk in and extend. Many doctoral students deviate from norms to improve aesthetic ethics. Queering doctoral pedagogy enables deviancies within doctoral learning to be recognized, sustained and supported.

\section{Conclusion}

The point is what we do with these moments of orientation, as well as what such moments can do--whether they can offer us the hope of new directions, or whether new directions are reason enough for hope. (Ahmed, 2006:

We suggest that queer theory can speak to the discomfort of doctoral transition and deviancy. It can also evoke the powerful erotic charge associated with embodied teaching and learning (Swan, 2005) and with research trail-blazing. We began by noting that queer and feminist desires are viewed as messy and disruptive. To those who feel desire, however, it nonetheless feels both right and compelling. New materialism defends the desire lines that drive some to push boundaries. Such deviants experience the potency of opening up new possibilities. It may well be messy, lonely and challenging, but that is how desire works.

Much that generalises doctoral learning is useful as a broad framework for doctoral study. We accept that doctoral-ness (e.g., as expressed in graduate attributes, critiqued by Barrie, 2007) provides a core identifier to each successful doctorate, but suggest that educationalists have tended to reinstate the normative and thus provide a partial understanding about how best to support PhD students. Further work using queer and 
nomadic subjectivity theories could bring a richer understanding to learning and pedagogy: the need for smooth progress and timely completions makes it worthwhile expanding the identification of what is generic about the doctoral experience to investigate and perhaps celebrate what is other, not-same, about the experience as well as the new knowledge. The theories we use here could be drawn upon in more depth.

Those who register for a doctoral degree inhabit bodies that lean in response to the societies they come from, the sexual and religious experiences (or 'post-secular' experience as Braidotti terms it in Delphijn and Van der Tuin, 2012: 30) that give their life meaning. It is pertinent to doctoral studies that 'Some bodies more than others have their involvement in the world called into crisis' (Ahmed, 2006: 159). They may be from indigenous or minority groups with family and community positions making transition into an embodied and performative academic identity uncomfortable (e.g., Brown and Watson, 2010; Carter, Blumenstein and Cook, 2013). Feminist or LGBTQ researchers will grapple out an identity between the disembodied positionality of theory and the embodied desires of their lives. Sometimes theory conflicts with lived experience; working that out often refines and redefines theory. Always the quest for new knowledge entails working amongst the notknown in a chaos needing to be ordered.

Doctoral processes potentially embody normativity, with bodily incorporations, and related essentializing tendencies (Gunn, 2014b). Queer theory offers a framework that transcends LGBTQ experience to validate doctoral learning, with its awkward discomfits and messiness, the lonely journeys pushing, often with misgiving, through new trails along borderlands. It suggests that desires which inspire wind our performativity, materiality and corporeality into a whole and this whole is where learning orientation is located.

\section{References}

Ahmed S and Stacey J (2001) Introduction: Dermographics. In: Ahmed S and Stacey J (eds) Thinking through the Skin. New York: Routledge, pp.1-17.

Ahmed S (2006) Queer Phenomenology: Orientations, Objects and Others. London: Duke University Press.

Aitchison C and Pare A (2012) Writing as craft and practice in the doctoral curriculum. In: Lee A and Danby R (eds) Reshaping Doctoral Education: International Approaches and Pedagogies. London: Routledge, pp.12-25.

Ali A and Kohun F (2007) Dealing with social isolation to minimize doctoral attrition: a four stage framework. International Journal of Doctoral Studies 2(no issue number): 3349.

Braidotti R (1996) Between Monsters, Goddesses and Cyborgs. London: Zed

Barrie SC (2007) A conceptual framework for the teaching and learning of generic graduate attributes. Studies in Higher Education 32(4): 439-458. 
Bartlett E and Bolt B (2013) Carnal Knowledge: Towards a 'New Materialism' in the Arts. London: I.B. Tauris.

Bolker J (1998) Writing your Dissertation in Fifteen Minutes a Day: A Guide to Starting, Revising, and Finishing Your Doctoral Thesis, 1st edn. New York: H. Holt.

Bracher M (2002) Identity and desire in the classroom. In: jagodzinski j (ed) Pedagogical Desire: Authority, Seduction, Transference, and the Question of Ethics. Milton Keynes, UK: Lightening Source, pp.93-121.

Brause RS (2000) Writing your Doctoral Dissertation: Invisible Rules for Success. London and New York: Falmer Press.

Brown L and Watson P (2010) Understanding the experience of female doctoral students. Journal of Further and Higher Education 34(3): 385-404.

Bruffee KA (1999) Collaborative Learning: Higher Education, Interdependence, and the Authority of Knowledge, 2nd edn. Baltimore: John Hopkins University Press.

Burford J (2015) Queer(y)ing the affective politics of doctoral education: toward complex visions of agency and affect. Higher Education Research and Development 34(4): 776-787.

Butler J (1990) Gender Trouble: Feminism and the Subversion of Identity. New York: Routledge

Cantwell R (2006) Thinking and writing for your thesis. In: Denholm C and Evans TD (eds) Doctorates Downunder: Keys to Successful Doctoral Study. Camberwell: Acer Press, pp.182-190.

Carter S (2012) Original knowledge, gender and the word's mythology: voicing the doctorate. Arts and Humanities in Higher Education 11(4): 406-417.

Carter S, Blumenstein M and Cook CM (2013) Different for women? the challenges of doctoral study. Teaching in Higher Education 18(4): 339-351.

Cherry NL (2005) Preparing for practice in the age of complexity. Higher Education Research and Development 24(4): 310-320.

Churchman D and King S (2009) Academic practice in transition: hidden stories of academic identities. Teaching in Higher Education 14(5): 507-516.

Delphijn D and Van der Tuin I (2012) Interview with Rosi Braidotti. In: Delphijn D and Van der Tuin I (eds) New Materialism: Interviews and Cartographies. Ann Arbour: Open University Press, pp.19-37.

Denholm CJ and Evans TD (2006) Doctorates Downunder: Keys to Successful Doctoral Study in Australia and New Zealand. Camberwell: Acer Press.

Dunleavy P (2003) Authoring a PhD: How to Plan, Draft, Write and Finish a Doctoral Thesis or Dissertation. Houndmills: Palgrave Macmillan.

Evans T (2010) Supervising part-time doctoral students. In: Walker M and Thomson P (eds) The Routledge Doctoral Supervisor's Companion: Supporting Effective Research in Education and the Social Sciences. Abingdon: Routledge, pp.131-137.

Grant BM (2003) Mapping the pleasures and risks of supervision. Discourse Studies in the Cultural Politics of Education 24(2): 175-190.

Greenblatt S (2005) Renaissance Self-Fashioning: From More to Shakespeare, 2nd edn. Chicago: University of Chicago Press.

Grimshaw T and Sears C (2008) 'Where am I from?' 'Where do I belong?': the negotiation and maintenance of identity by international students. Journal of Research in Higher Education 7(3): 259-278.

Grosz, E (2010) Feminism, Materialism, and Freedom. In: Coole, D and Frost, S (eds) New Materialisms: Ontology, Agency, and Politics. London: Duke University Press, pp.139-157. 
Gunn VA and McAllister C (2013) Methods on the margins? queer theory as 'method' in higher education. In: Tight $\mathrm{M}$ and Huisman $\mathrm{J}$ (eds) Theory and Method in Higher Education Research. London, Emerald, pp.155-174.

Gunn VA (2014a) Desire seeking the self: queering doctoral education to understand orientations to learning. Paper presented at the Society for Research into Higher Education Annual Conference, Newport, UK, December 10-12.

Gunn VA (2014b) Managing 'straight' PhDs from queer places: generic support for LGBT students. In: Carter S and Laurs D (eds) Developing Generic Support for Doctoral Students: Practice and Pedagogy. Abingdon: Routledge, pp.53-56.

Halberstam J (1998) Female Masculinity. Durham, Duke University Press.

Hopwood N and Paulson J (2012) Bodies in narratives of doctoral students' learning and experience. Studies in Higher Education 36(7): 667-681.

Ings W (2015) Performing prodigals and dissent acolytes: supporting queer postgraduates in the visual arts. Higher Education Research and Development 34(4): 735-749.

Kamler B and Thomson P (2006) Helping Doctoral Students Write: Pedagogies for Supervision. London: Routledge.

Keane, J. (2013) Æffect: initiating heuristic life. In: Bartlett E. and Bolt B. (eds) Carnal Knowledge: Towards a 'New Materialism' in the Arts. London: I.B. Tauris, pp. 4161.

Kiley M and Wisker G (2009) Threshold concepts in research education and evidence of threshold crossing. Higher Education Research and Development 28(4): 431-441.

Kirby V (1994) Response to Jane Gallop's “The Teacher's Breasts”: bad form. In: Matthews JJ (ed) Jane Gallop Seminar Papers: Proceedings of the Jane Gallop Seminar and Public Lecture 'The Teacher's Breasts'. Canberra: Humanities Research Centre, pp.17-22.

Laurs D (2013) Thesis writing: the paradox of same, same but different. In: DoctoralWriting SIG. Available at: https://doctoralwriting.wordpress.com/2013/11/29/thesis-writingthe-paradox-of-same-same-but-different/ (accessed 22 October 2015).

Lee A and Aitchison C (2009) Writing for the doctorate and beyond. In: Boud D and Lee A (eds) Changing Practices of Doctoral Education. Abingdon: Routledge, pp.87-99.

Lovitts BE (2008) The transition to independent research: who makes it, who doesn't, and why. Journal of Higher Education 79(3): 296-325.

Lovitts BE and Nelson C (2000) The hidden crisis in graduate education: attrition from Ph.D. programs. Academe 86(6): 44-50.

Maclure M (2009) Broken voices, dirty words: on the productivity of the voice. In: Jackson AY and Mazzei LA (eds) Voice in Qualitative Inquiry: Challenging Conventional, Interpretive, and Critical Conceptions in Qualitative Research. New York and Abingdon: Routledge, pp.97-114.

Maritz J and Prinsloo P (2015) 'Queering' and querying academic identities in postgraduate education. Higher Education Research and Development 34(4): 695-708.

Marsh DR, Schroeder DG, Dearden KA, Sternin J and Sternin M (2004) The power of positive deviancy. British Medical Journal 329(7474): 1177-1179.

Martusewicz RA (1997) Say me to me: desire and education. In: Todd S (ed) Learning Desire: Perspective on Pedagogy, Culture and the Unsaid. New York: Routledge, pp 183-204.

Melin Emilsson E and Johnsson E (2007) Supervision of supervisors: on developing supervision in postgraduate education. Higher Education Research and Development 26(2): 163-179. 
Meyer JHF and Land R (2005) Threshold concepts and troublesome knowledge (2): epistemological considerations and a conceptual framework for teaching and learning. Higher Education 49(3): 373-388.

Munt S (1998) Heroic Desires: Lesbian Identity and Cultural Space. London: Cassell. Murray R (2011) How to Write a Thesis, 3rd edn. Berkshire: Open University Press.

Petersen BE (2007) Negotiating academicity: postgraduate research supervision as category boundary work. Studies in Higher Education 32(4): 475-487.

Riddy F (1994) The speaking knight: Sir Gawain and other animals. In: Shichtman MB and Carley JP (eds) Culture and the King: The Social Implications of the Arthurian Legend. Albany: State University of New York Press, pp.149-162.

Smith LT (1999) Decolonizing Methodologies: Research and Indigenous Peoples. New York: Zed Books.

Sparkes A (2007) Embodiment, academics and the audit culture: a story seeking consideration. Qualitative Research 7(4): 521-550.

Spreitzer GM and Sonenshein S (2004) Towards the construct definition of positive deviance. American Behavioural Scientist 47(6): 828-847.

Swan E (2005) On bodies, rhinestones, and pleasures: women teaching managers. Management Learning 36(3): 317-333.

Thesen L (2014) 'If they're not laughing, watch out!': emotion and risk in postgraduate writers' circles. In: Aitchison C and Guerin C (eds) Writing Groups for Doctoral Education and Beyond: Innovations in Practice and Theory. Abingdon and New York: Routledge, pp.162-176.

Thomson P and Walker M (2010) The Routledge Doctoral Student's Companion: Getting to Grips with Research in Education and the Social Sciences. London: Routledge.

Toynton R (2007) The de-representation of science and queer science students in higher education within the queer/gay discourse. Teaching in Higher Education 12(5-6): 593-606.

Walker M (2010) Doctoral education as a 'capability' formation. In: Walker M and Thomson $\mathrm{P}$ (eds) The Routledge Doctoral Supervisor's Companion: Supporting Effective Research in Education and the Social Sciences. Abingdon and New York: Routledge, pp.29-37.

Watts JH (2010) Supervising part-time doctoral students: Issues and challenges. In: M. Walker, and P. Thomson (eds), The Routledge Doctoral Supervisor's Companion: Supporting Effective Research in Education and the Social Sciences. Oxon: Routledge, pp.123-130.

Webber M (2009) The multiple selves and realities of a Maori researcher. Maori and Indigenous Review 1(no issue number): 1-8.

White B (2011) Mapping Your Thesis: The Comprehensive Manual of Theory and Techniques for Masters and Doctoral Research. Camberwell: Acer Press.

Wisker G (2012) The Good Supervisor. New York: Palgrave Macmillan.

Wisker G, Cheng M and Morris C (2010) Nudging: Conceptual threshold crossing in doctoral learning journeys. Paper presented at Society of Research into Higher Education Conference, Newport, UK, December 14-16.

Wu S (2013) Filling the pot or lighting the fire: cultural variations in conceptions of pedagogy. Teaching in Higher Education 7(4): 387-395. 